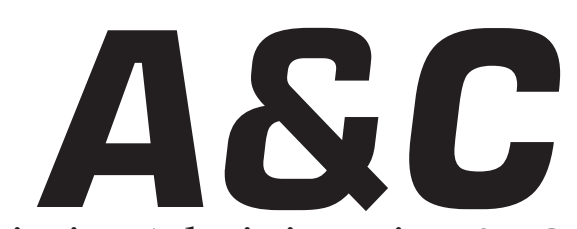

Revista de Direito Administrativo \& Constitucional

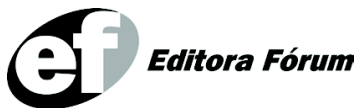

ISSN 1516-3210

A\&C R. de Dir. Administrativo e Constitucional Belo Horizonte ano 8 n. 31 p. 1-272 jan./mar. 2008 


\section{A\&C - REVISTA DE DIREITO ADMINISTRATIVO E CONSTITUCIONAL}

IPDA

Instituto Paranaense

de Direito Administrativo

Direção Geral

Romeu Felipe Bacellar Filho

Direção Editorial

Paulo Roberto Ferreira Motta

Direção Executiva

Emerson Gabardo

Conselho de Redação

Edgar Chiuratto Guimarães

Adriana da Costa Ricardo Schier

Célio Heitor Guimarães

\section{Conselho Editorial}

Adilson Abreu Dallari

Alice Gonzáles Borges

Carlos Ari Sundfeld

Carlos Ayres Britto

Carlos Delpiazzo

Cármen Lúcia Antunes Rocha

Celso Antônio Bandeira de Mello

Clèmerson Merlin Clève

Clóvis Beznos

Enrique Silva Cimma

Eros Roberto Grau

Fabrício Motta

Guilhermo Andrés Muñoz (in memoriam)

Jaime Rodríguez-Arana Muñoz

Jorge Luís Salomoni

José Carlos Abraão
José Eduardo Martins Cardoso
José Luís Said
José Mario Serrate Paz
Juan Pablo Cajarville Peruffo
Juarez Freitas
Julio Rodolfo Comadira
Luís Enrique Chase Plate
Lúcia Valle Figueiredo
Manoel de Oliveira Franco Sobrinho
(in memoriam)
Marçal Justen Filho
Marcelo Figueiredo
Márcio Cammarosano
Maria Cristina Cesar de Oliveira

Nelson Figueiredo

Odilon Borges Junior

Pascual Caiella

Paulo Eduardo Garrido Modesto

Paulo Henrique Blasi

Paulo Neves de Carvalho (in memoriam)

Paulo Ricardo Schier

Pedro Paulo de Almeida Dutra

Regina Maria Macedo Nery Ferrari

Rogério Gesta Leal

Rolando Pantoja Bauzá

Sérgio Ferraz

Valmir Pontes Filho

Yara Stropa

Weida Zancaner

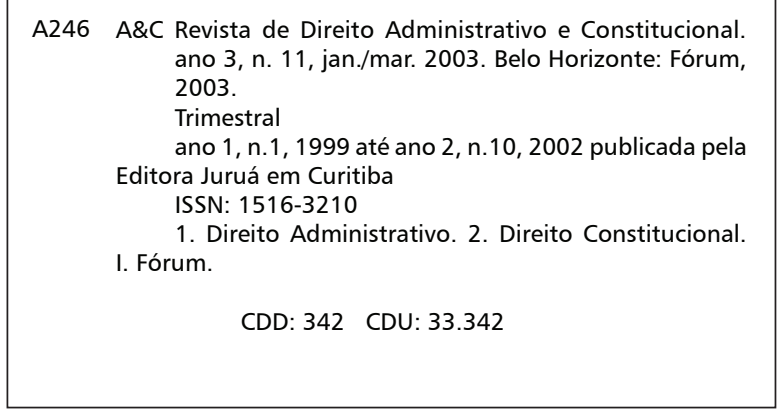

(c) Editora Fórum Ltda. 2008

Todos os direitos reservados. É proibida a reprodução total ou parcial, de qualquer forma ou por qualquer meio eletrônico ou mecânico, inclusive através de processos xerográficos, de fotocópias ou de gravação, sem permissão por escrito do possuidor dos direitos de cópias (Lei $n^{\circ}$ 9.610, de 19.02.1998).

Editora Fórum Ltda.

CEP 30130-007 - Belo Horizonte/MG - Brasil

Tel.: 08007043737

Internet: www.editoraforum.com.br

e-mail: editoraforum@editoraforum.com.br
Av. Afonso Pena, 2770 - 15\%/16 andar - Funcionários

Editor responsável: Luís Cláudio Rodrigues Ferreira

Coordenação editorial: Olga M. A. Sousa

Projeto gráfico e diagramação: Luis Alberto Pimenta

Revisoras: Carolina Rocha

Lourdes Nascimento

Pesquisa jurídica: Fátima Ribeiro - OAB/MG 74868

Bibliotecárias: Fernanda de Paula Moreira

Leila Aparecida Anastácio - CRB 2513 - 6ª região

Os conceitos e opiniões expressas nos trabalhos assinados são de responsabilidade exclusiva de seus autores.

Impressa no Brasil / Printed in Brazil

Distribuída em todo o Território Nacional 


\title{
La Función Administrativa en la Constitución Chilena
}

\author{
Rolando Pantoja Bauzá \\ Catedrático de Derecho Administrativo. Presidente del Centro de Altos Estudios Administrativos \\ Facultad de Derecho - Universidad de Chile.
}

Palabras clave: Chile. Constitución chilena. Funcion administrativa. Servicio público.Tesis garantística individual.

Índice: I Antecedentes - II La concepción de la función administrativa bajo la Constitución de 1980: el criterio del servicio público y la tesis garantística individual - III La concepción de la función administrativa bajo la Constitución de 2005: una función administrativa para el desarrollo social, cultural y económico de la nación, las regiones y las comunas - IV El eje funcional de lo administrativo en el texto vigente de la Constitución Política: la redefinición de las funciones de gobierno y de administración del Estado formulada por la ley $\mathrm{m}^{\circ}$ 19.097, de 1991 - V La sustancialidad de los derechos en su proyección funcional administrativa: el desarrollo de todos los miembros de la comunidad nacional

\section{Antecedentes}

La Constitución chilena responde a los criterios generales aceptados por el constitucionalismo clásico, como que se estabilizó en el ambiente político jurídico de 1833, en el texto de la Carta Política de ese año, la que sintomáticamente se planteó ab initio como una gran modificación de su predecesora, la de 1828, iniciándose así una práctica constitucional que habría de marcar una pauta de técnica jurídica para el futuro, como que los demás Códigos Políticos que desde entonces han regido la República han seguido ese modo de proceder planteándose a sí mismas como sucesivas modificaciones de las Cartas anteriores a ellas. El modelo de las Constituciones de esta época se encontraba en las Cartas francesas de 1791 y 1793, y en la Constitución de Cádiz de 1812, y a ellas acudieron los constituyentes de la Gran Convención de 1833.

En efecto, la Constitución de 1925, que sucedió a la de 1833, fue otra gran modificación constitucional, obra de cirugía mayor practicada al texto de 1833. La Carta de 1980, que elaboró una Comisión de Estudio designada en 1973 por el Gobierno Militar, también siguió ese iter: tomó como modelo la Constitución de 1925 y la puso al día a ese año buscando recoger e incorporar a su cuerpo normativo las experiencias y valores de país, así como las expresiones constitucionales incorporadas a los Códigos Políticos de los países europeos.

A \& C R. de Dir. Administrativo \& Constitucional, Belo Horizonte, ano 8, n. 31, p. 180-198, jan./mar. 2008 
La Constitución chilena al año 2005, por su parte, es sólo la edición actualizada de la Constitución de 1980, a cuyo cuerpo normativo se le han agregado ordenadamente las diversas modificaciones que le ha introducido el constituyente en los últimos quince años.

2 Este conservadurismo constituyente ha traído consigo un consecuente conservadurismo doctrinal en la apreciación de las funciones del Estado, y se ha mantenido así no obstante las tensiones que imprimen a esas estructuras y funcionalidades las exigencias de los tiempos contemporáneos que las impactan, circunstancias que cuando no desfiguran el trazado de su diseño promueve actitudes heterodoxas por parte de los protagonistas de la escena política, en particular las autoridades elegidas directamente por los ciudadanos, como son los alcaldes y concejales, los diputados y senadores.

3 Atendidos estos antecedentes, no ha de extrañar que pueda calificarse a la Constitución chilena como una Carta conservadora. También lo es la doctrina ius administrativa que desarrolla la razón de ser de la función administrativa del Estado, hasta el punto que como se verá, la reforma constitucional de 1991, que es importante en este aspecto, aún no ha sido decepcionada generalizadamente por ella.

Ello explica que el constituyente chileno, siguiendo su modelo ilustrado, haya confiado y siga confiando al Presidente de la República, Jefe de Estado y Jefe de Gobierno en el país, el ejercicio de las funciones de gobierno y de administración, como lo reitera en la actualidad el artículo 24 de la Constitución de 2005 al expresar que "El gobierno y la administración del Estado corresponden al Presidente de la República, quien es el Jefe del Estado."

Explica, asimismo, la actitud que asumió frente a la organización administrativa, al rehuir una normativa coherente que la regule y mantener una porfiada parquedad sobre la materia, que lo hace limitarse sólo a dos vías de referencia, una, para destacar la existencia en el organigrama administrativo, de los servicios fiscales, semifiscales y las empresas del Estado (artículo 65, inciso $4^{\circ}$, numeral $2^{\circ}$, en su texto original de 1980); la otra, para llamar al legislador orgánico constitucional a determinar la "organización básica de la Administración Pública" (artículo 38, inciso 1º).

Basada en el artículo 24 antes citado, la jurisprudencia administrativa y la doctrina sostuvieron que la determinación de la naturaleza jurídica de un órgano del Estado, obligaba a recurrir, en primer término, "a las disposiciones constitucionales que se refieren a los organismos integrantes 
de la Administración del Estado". "A este respecto puede afirmarse que el Presidente de la República, en el ejercicio de la función de administrar el Estado que le encomienda en forma privativa la Carta Fundamental, debe recurrir a los únicos organismos que la misma Carta señala como ejecutores de esta facultad" (dictamen $n^{\circ} 55.741$, de 1957).

Y don Enrique Silva Cimma, coincidiendo con esta apreciación, dirá en 1959, que los servicios personificados de la Administración dependían del Presidente de la República por constituir parte de la Administración central. "La administración central, expresa el señor Silva, está formada por los servicios fiscales, los servicios con régimen de autonomía, las instituciones y las empresas públicas". ${ }^{1}$

La Ley Orgánica Constitucional de Bases Constitucionales de la Administración del Estado, enfatizando esta presidencialización de lo administrativo, reconoce en su artículo $1^{\circ}$ que la summa de estas atribuciones está radicada en el Presidente de la República, llegando a decir que los demás órganos que componen la estructura administrativa no son más que sus colaboradores en el despliegue de esa misión.

Artículo $1^{\circ}$, inciso $1^{\circ}$. El Presidente de la República ejerce el gobierno y la administración del Estado con la colaboración de los órganos que establezcan la Constitución y las leyes.

Dentro de este orden de ideas, un organismo será administrativo cuando haya recibido previamente el óleo y el crisma administrativos de manos del Presidente de la República, tanto en su creación, puesto que sólo puede nacer por ley de iniciativa del Jefe de Estado, cuanto en su actuación, ya que después, una vez nacido al mundo del Derecho, ese órgano queda vinculado permanentemente al Presidente de la República por un vínculo de jerarquía o supervigilancia, como lo reconoce el artículo 29 de aquella Ley Orgánica Constitucional, al definir a los servicios centralizados como aquellos que actúan "bajo la personalidad jurídica y con los bienes y recursos del Fisco y estarán sometidos a la dependencia del Presidente de la República, a través del Ministerio correspondiente", y a los servicios descentralizados como a los que actúan "con la personalidad jurídica y el patrimonio propio que la ley les asigne y estarán sometidos a la supervigilancia del Presidente de la República”, por la misma vía que

Silva Cimma, Enrique, Apuntes de Derecho Administrativo, Editorial Universitaria S.A., 1958, p. 241, 273 y 274.

A \& C R. de Dir. Administrativo \& Constitucional, Belo Horizonte, ano 8, n. 31, p. 180-198, jan./mar. 2008 
los centralizados, fiscales o dependientes.

II La Concepción de la Función Administrativa bajo la Constitución de 1980: El criterio del servicio público y la tesis garantística individual

4 Teniendo como telón de fondo este paisaje constitucional, la doctrina chilena de Derecho Administrativo presenta desde 1925 en adelante, para fijar una divisoria constitucional de aproximación significativa, dos grandes corrientes teóricas: la del servicio público, de fuente social, y la garantística, de inspiración individual.

\section{A) La definición orgánica o estructural: la función administrativa es una actividad de servicio público}

Estimulada tal vez por la presencia en Chile del profesor Gastón Jèze en la década de 1920, la doctrina chilena de la primera mitad del siglo XX se inclinó sensiblemente hacia la escuela realista francesa que inauguró el granDecano de Burdeos León Duguit, con su insuperada recreación jurídica del solidarismo que apuntó en el siglo XX, y según la cual la función administrativa es una actividad del Estado orientada a satisfacer necesidades públicas de manera regular y continua, y conforme a un procedimiento de Derecho Público.

La influencia francesa habría de manifestarse explícitamente en las obras de los profesores Manuel Jara Cristi y Guillermo Varas Contreras, de 1943 y 1948, respectivamente, en particular en la del señor Varas Contreras, quién advertía en su tiempo un bajo desarrollo de la disciplina en el país frente a las magnitudes que alcanzaba el diseño del profesor Gastón Jèze, cuya tesis representaba para él un modelo de construcción del Derecho Administrativo y su verdadera expresión científica como disciplina del Derecho.

"El estudio del Derecho Administrativo - dice el profesor Varas ha gozado de muy poco favor en el país, tanto por el desconocimiento de su carácter científico, como por la escasa importancia que hasta hace poco se le atribuía en la práctica profesional." A su juicio, "la creciente intervención del Estado - que se advertía con fuerza en aquella época-ha dado al Derecho Administrativo un relieve e importancia cada vez mayor", la que unida a los "numerosos antecedentes de jurisprudencia y de doctrina" que había reunido eran suficientes para "afirmar que ya existe en nuestro 
país un Derecho Administrativo consagrado por resoluciones judiciales y administrativas de notoria importancia”, las que estima necesario sistematizar poniendo "de relieve las instituciones jurídico-administrativas, frente a las que el Código Civil establece, señalando sus características y sus procedimientos propios". ${ }^{2}$

La tesis de esos años habría de ser seguida por los libros inmediatamente posteriores al "Derecho Administrativo" del señor Varas Contreras, obra por lo demás justamente celebrada y destacada dentro de la bibliografíanacional por su ordenada exposición y razonado contenido. Así, v.gr., el profesor Patricio Aylwin Azócar, al año 1959, definiría el Derecho Administrativo diciendo que "es el que rige la organización y funcionamiento de los servicios públicos", habida consideración de ser el servicio público "el mecanismo o procedimiento especial de que se vale el Estado para realizar la actividad administrativa destinada a cumplir sus tareas o cometidos". ${ }^{3}$

Esta perspectiva de lo administrativo, unida a una fuerte tradición constitucional de separación de los poderes públicos, induciría a la jurisprudencia administrativa a sostener que la Administración del Estado "es un término genérico que comprende a todos los servicios mediante los cuales el Presidente de la República cumple con su función de administrar el Estado que la Constitución le encomienda”, como lo señaló el dictamen $\mathrm{n}^{\circ} 50.423$, de 1960, de la Contraloría General de la República, y al profesor Arturo Aylwin Azócar, en 1980, a constatar, en un criterio que era y es el que ha circulado desde siempre en los ámbitos especializados del país, que "cuando en la legislación o en el lenguaje diario se habla de administración o de administración del Estado, se está refiriendo precisamente a ese término en sentido orgánico. En consecuencia, la Administración del Estado, denominada en muchas ocasiones como Administración Pública o en otras con la sola palabra Administración, comprende a todos los órganos e instituciones del Estado que realizan función administrativa". ${ }^{4}$

De aquí que se generalizara en el Derecho chileno la aceptación de una perspectiva orgánica de la administración pública que desplazó a un segundo plano su caracterización funcional, dando un lugar prioritario al diseño estructural de la Administración, al acotar lo administrativo en

\footnotetext{
Varas Contreras, Guillermo, Derecho Administrativo, Editorial Nascimento, 1948, p. 5-8.

Aylwin Azócar, Patricio, Derecho Administrativo, tomo I, op.cit., p. 16-17.

Aylwin Azócar, Arturo, Apuntes de Derecho Administrativo, Contraloría General de la República, 1980, p. 39.
}

A \& C R. de Dir. Administrativo \& Constitucional, Belo Horizonte, ano 8, n. 31, p. 180-198, jan./mar. 2008 
torno a su ser esquemático, a su organigrama, lo cual implicaba afirmar, desde luego, que todo cuanto realice este complejo orgánico, por ese solo hecho, pasaba a adquirir un consecuente carácter administrativo, en tanto y en cuanto, naturalmente, se encontrare regido por el Derecho Público, característica consustancial a su ser jurídico.

\section{B) La definición subjetiva o garantística: la función administrativa es sólo ejecución de ley}

La filosofía gubernamental de los años 1973-1990, proclamada como guía de su acción política por el Gobierno Militar, habría de rechazar las visiones jurídico administrativas que le habían precedido, imputándoles adolecer de un entronque estatista, para proclamar, en la "Declaración del Gobierno de Chile", de 11 de marzo de 1974, y en los "Objetivos del Gobierno de Chile", de 23 de diciembre de 1975, su respeto a "la concepción cristiana sobre el hombre y la sociedad" y su convicción de ver al hombre como "un ser dotado de espiritualidad", lo que le da "verdadero fundamento - a-la dignidad de la persona humana" y la hace per se "superior al Estado" y sujeto de derechos naturales que "tienen su origen en el propio Creador", entre ellos, en particular, "el derecho de propiedad privada" sobre los bienes de consumo y de producción, lo que habría de hacer del país un país de "propietarios" y no de "proletarios", asignando al Estado sólo una actuación supletoria de la acción de los privados, en los lugares o sectores donde éstos no quisieran o no pudieran hacerlo.

$\mathrm{Al}$ amparo de esta tesis, profesores del ramo se sintieron estimulados a plantearse el Derecho Administrativo en términos diferentes a los conocidos hasta entonces por la doctrina, moldeándolo, en definitiva, como un Derecho garantizador de la individualidad.

Formulada la discrepancia, se ha dicho, el administrativismo de los años 1973 en adelante, criticó "con arrestos de cientificidad y arrojos de descalificación", ${ }^{5}$ al legislador, a la doctrina y a la jurisprudencia precedentes.

Al legislador, porque "no suele ser infrecuente el que legisladores apresurados, por no decir frívolos, traten de insertar en nuestro ordenamiento instituciones o mecanismos jurídico-políticos extranjeros que poco o nada se avienen con nuestro sistema, tradiciones o idiosincrasia".

A la doctrina, por ser "muy frecuente entre los hombres dedicados

Pantoja Bauzá, Rolando, El Derecho Administrativo, cit., p. 165-166.

A \& C R. de Dir. Administrativo \& Constitucional, Belo Horizonte, ano 8, n. 31, p. 180-198, jan./mar. 2008 
al Derecho en nuestra patria, buscar los orígenes de las instituciones públicas o político-jurídicas en Francia o Estados Unidos, olvidando... que Chile -estuvo-regido por el derecho castellano indiano". ${ }^{6}$

"Cuidado siempre, siempre cuidado - se advertirá - con los presentes griegos, injertos extranjerizantes, con las baratijas o abalorios con que pretenden regalarnos aquellos nuevos ricos del intelecto recién llegados al banquete de la ciencia, que engolosinados con lo extranjero desprecian la propia riqueza de nuestras tradiciones". ${ }^{7}$

A la jurisprudencia, en tanto "la interpretación de los jueces" contribuyó a "tronchar y gravemente este desarrollo de la juridicidad del actuar del Estado/administrador — que venía de 1833 —, rompiendo abruptamente esa tradición de respeto a la ley de autoridades y funcionarios", inconsecuencia que habría de desembocar en "la destrucción de una estructura que en sus bases estableciera precisamente 140 años antes la inteligencia visionaria de Portales, patriota sin tacha y modelo de virtudes ciudadanas, las mismas de que carecieron los que frívola e inconscientemente destruyeran, imbuidos de ideologías extranjeras, la institucionalidad de la República". 8

Desde esta perspectiva innovadora y nacionalista, la nueva tendencia doctrinal practicó una cirugía a fondo a la fundamentación e institucionalización administrativas hasta entonces admitidas como válidas en el ámbito ius administrativo, haciéndolas en definitiva funcionales a los nuevos protagonistas de la vida socioeconómica del país.

"El Derecho Administrativo — se dijo —, más que estar configurado por un conjunto de normas reguladoras de las potestades administrativas y en donde todas sus instituciones giran en torno al Estado - ha de entenderse - como el derecho de la libertad del ciudadano frente a la autoridad". ${ }^{9}$

"Hoy tenemos que habérnosla — se agregó - con un Derecho Administrativo que no coloca el acento en el Estado y sus atribuciones, sino en

\footnotetext{
6 Soto Kloss, Eduardo, Derecho Administrativo, tomo II, Editorial Jurídica de Chile, 1996, p. 130.

7 Soto Kloss, Eduardo, La nulidad de derecho público en el Derecho Público chileno, Gaceta Jurídica, n. 125, 1990.

8 Soto Kloss, Eduardo, Administración y Derecho en Chile, Revista de Derecho Público, n. 33/34, Facultad de Derecho, Universidad de Chile, enero/diciembre,1983, p. 53 y sgts.

9 La filosofía de ese tiempo, confesaría una destacada figura política del Gobierno Militar, asesora de la Presidencia de la República y luego titular endos Ministerios, buscaba "reducir el Estado a términos de tanta insignificancia que no pudiese el día de mañana amagar las pretendidas libertades. ElEstado tenía que ser un ente sin poder alguno, que tuviese que golpear las puertas de los vecinos de la sociedad para pedirles prestado un poco de supropia fuerza para adoptar cualquiera iniciativa. De lo que se trataba era de transformar en ineficiente al Estado". En revista Análisis, año IX, n. 120, 10 al 16 dic. 1985: Mónica Madariaga pide perdón, p. 19.
} 
el ciudadano y sus libertades", ${ }^{10}$ y hay necesidad, entonces, de superar la anterior corriente de pensamiento surgida de la tesis orgánica del servicio público, por hallarse dominada por un "slogan colectivista y estatizante en boca de seudojuristas"; de "propugnadores o adalides -que-tenían in mente confesadamente o in pectore fines colectivistas", en "cátedras de Derecho Administrativo -dominadas por una-extrema ligereza intelectual"; ${ }^{11}$ y haberse desarrollado al amparo de un "frío dogmatismo positivista corrompido en sus bases por una seudotecnología positiva" proveniente de "la visión revolucionaria de 1789 y afrancesada, que nada tiene que ver con nuestra tradición castellano-indiana”, ni con "nuestra propia idiosincrasia jurídica y nuestras propias tradiciones". ${ }^{12}$

En lo constructivo, esta orientación doctrinal abogó intransigentemente por el reconocimiento irrestricto de los derechos de los particulares frente a la Administración, presentando a la función administrativa como una actividad de mera "ejecución de las leyes para la realización del bien común", ${ }^{13}$ anclada en un severo principio de la legalidad definido como necesaria habilitación legal previa para toda actuación administrativa, bajo pena de nulidad de Derecho Público en supuestos de inobservancia o contravención, y aceptando que la función administrativa era una actividad de estricta ejecución de ley.

"Y icuidado! con entender — se previno - que porque el texto constitucional diga - respecto del Presidente de la República, que puede dictar los decretos y reglamentos — "que crea convenientes" para dicha ejecución, el Presidente queda liberado de su obligación constitucional y puede actuar cuando se le ocurra según su capricho, bon vouloir,o beneplácito, al modo de un monarca absoluto, porque la propia Constitución, que es republicana y no monárquica como algunos parecen creer, se encarga de hacer jurídicamente responsable al mismo Presidente". ${ }^{14}$

\footnotetext{
10 Esta cita y la opinión transcrita inmediatamente supra en el texto, corresponden a Aróstica Maldonado, Iván, ¿Qué queda de la presunción delegalidad?, Revista de Derecho y Jurisprudencia, tomo 88, primera parte, p. 1 .

11 Véase: Soto Kloss, Eduardo, Los derechos adquiridos en el Derecho Público chileno, Revista de Derecho y Jurisprudencia, tomo 81, n. 1, 1984, primera parte, p. 13, 19 y 23.

12 Véase: Soto Kloss, Eduardo, La invalidación de los actos administrativos en el Derecho chileno, Revista de Derecho, Jurisprudencia y Ciencias Sociales, tomo 85, n. 3, 1988, primera parte, p. 157; y el comentario a la sentencia recaída en el recurso de protección interpuesto la Empresa de Residuos Resiter y Cia., en la misma Revista, tomo 88, n. 2, 1991, segunda parte, sección quinta, p. 169.

13 Caldera Delgado, Hugo, Manual, op. cit. p. 34.

14 Soto Kloss, Eduardo, Comentario al fallo recaído en el recurso de protección deducido por la Administradora de Inversiones y Supermercados Unimarc S.A., publicado en la Revista de Derecho y Jurisprudencia, tomo 88, n. 2, segunda parte, sección quinta, p. 205
} 
De aquí que al pronunciarse como abogado integrante del Tribunal Constitucional sobre un proyecto de ley que remitía al reglamento "los requisitos y especificaciones técnicas" de los fuegos artificiales, artículos pirotécnicos y otros artefactos similares que quedaban sujetos a control, uno de los profesores adherentes a esta corriente de pensamiento votara en contra de dicho artículo, por constituir, a su juicio, la "importación, fabricación, transporte, almacenamiento o distribución" de esos bienes, "el ejercicio de un derecho básico e inherente a la naturaleza humana, como es el de desarrollar actividades económicas, fruto directo de la primacía de la persona, que sólo puede ser regulado por el legislador a través de la ley y jamás por acto administrativo, como es en este caso, en que se pretende hacerlo por un reglamento". ${ }^{15}$

En el ámbito de la organización administrativa, esta tendencia excluyó a la teoría del servicio público de los programas universitarios de estudio e incorporó a ellos, en su lugar, un capítulo referido a las personas jurídico administrativas, dirigidas por autoridades unipersonales, jamás por órganos colegiados. “¿Cómo puede pretenderse — se exclamó — que en la administración - de los organismos administrativos - tengan participación, voz y voto, usuarios, y sobre todo organizaciones profesionales? Parece excesivo y recuerda engendros de triste memoria", al margen de ser, en sí misma, una posibilidad "demencial". ${ }^{16}$

Hay que "mostrar en lo técnico jurídico — se aseverará — cómo la Administración del Estado, más que un conjunto de servicios públicos centralizados y descentralizados, noción por lo demás difícil de asir jurídicamente y de escasa utilidad operativa en lo organizacional, es un conjunto de personas jurídicas estatales, públicas, administrativas", por ser ésta "la correcta manera de plantearse jurídicamente el problema de la organización administrativa". ${ }^{17}$

La aireada proclamación de "lo técnico jurídico" como elemento constructivo del Derecho Administrativo en un ambiente de dominancia tecnocrática, los programas de estudios universitarios pasaron a ignorar el servicio público para presentar a la Administración del Estado organizada

\footnotetext{
15 Véase: Tribunal Constitucional de Chile, Jurisprudencia constitucional, tomo V, 1998-2002, Fallo Rol 306, de 2000, p. 223.

${ }^{16}$ Soto Kloss, Eduardo, en Actas oficiales de la Nueva Constitución, sesión 108 ${ }^{a}$, de 25 de marzo de 1975, p. 29 y 35.

17 Soto Kloss, Eduardo, La organización de la Administración del Estado: un complejo de personas jurídcas, Gaceta Jurídica, n. 73, 1986, p. 16 ysgts.
}

A \& C R. de Dir. Administrativo \& Constitucional, Belo Horizonte, ano 8, n. 31, p. 180-198, jan./mar. 2008 
como un "conjunto de personas jurídicas estatales", erradicando a la función administrativa como actividad de servicio público para reinstalar a la ejecución de la ley como el núcleo de la función administrativa del Estado.

Estas convicciones llevaron a constatar a sus partícipes un "notable repunte del derecho público chileno" ${ }^{18}$ por aquellos años, "una perspectiva en que el Derecho ha sido iluminado por una buena nueva... - por-lo perenne de lo humano, pero vivificado por la luz de Cristo", ${ }^{19}$ llevándolos a congratularse de ser protagonistas de la exaltación del "papel eminentemente tutelar o protector del derecho administrativo respecto de los administrados", prescindiendo de "los aspectos organizacionales", cuyo tratamiento "no beneficia en modo alguno - al-propósito rector — de la disciplina, que es el de-mostrar a los particulares la forma en que pueden amparar sus derechos por medio del conocimiento de los requisitos indispensables que tiene que respetar la autoridad en el ejercicio de sus poderes jurídicos exorbitantes del derecho privado común y de la forma en que pueden impugnarse las resoluciones administrativas cuando ellas son arbitrarias". ${ }^{20}$

\section{La Concepción de la Función Administrativa bajo la Constitución de 2005: una administración para el desarrollo social, cultural y económico de la nación, las regiones y las comunas}

5 Si bien la Constitución de 2005, como se ha manifestado, es un texto refundido que recoge las normas de la Carta de 1980 y las numerosas modificaciones que posteriormente fueron incorporadas a su texto, lo que sin duda la presenta a primera vista como un ordenamiento constitucional simplemente ordenador de normas sin carácter innovativo alguno, la verdad es que su análisis sustancial y las circunstancias históricas que convergen en ella, llevan a considerarla como una verdadera Constitución del país, en la medida que sus diferencias con la de 1980 marcan la línea divisoria que separa el Autoritarismo Militar del Gobierno 1973-1990 y sus contenidos político jurídicos, de los contenidos y regulaciones que aprobó la Civilidad en Democracia, al asumir por elección popular el gobierno

\footnotetext{
18 Soto Kloss, Eduardo, Ordenamiento constitucional, Introducción, Editorial Jurídica de Chile, 1980, p. 7

19 Soto Kloss, Eduardo, La responsabilidad extracontractual del Estado Administración, un principio general del Derecho chileno, Revista de Derecho Público, n. 21/22, 1977, p. 149-156. , La responsabilidad pública: enfoque político (Un retorno a la idea clásica de institución), en "Responsabilidad del Estado", Ediciones UNSTA, Tucumán, Argentina, 1982; p. 28, 18-19, 25, 25 nota 15, y 19.

20 Caldera Delgado, Hugo, Manual, op.cit., p. 7 -8.
} 
de la República en marzo del año 1991. En efecto, la coexistencia de un Presidente de la República y de Congreso Nacional elegidos por votación popular como representantes de las diversas sensibilidades del país, hacen que las modificaciones que discurren en el constitucionalismo desde ese año en adelante surjan como consecuencia de una verdadera convergencia de puntos de vista respecto de los grandes temas nacionales, haciendo de la Carta de 2005, a la fecha, la expresión fidedigna de la nueva manera de ser del mundo público chileno en consenso democrático.

IV El Eje Funcional de lo Administrativo en el texto vigente de la Constitución Política: la redefinición de las funciones de gobierno y de administración del Estado formulada por la Ley $n^{\circ} 19.097$, de 1991

6 En este nuevo ambiente pos 1990, el punto de vista orgánico, estructural o subjetivo que había dominado el campo público administrativo, habría de verse drásticamente modificado ya el año 1991, al dictarse la ley de reforma constitucional $\mathrm{n}^{\circ} 19.097$, de ese año, que reestructuró el Capítulo XIII de la Carta Política sobre "Gobierno y Administración Interior del Estado".

Junto con democratizar las instituciones territoriales, esta reforma constitucional incorporó al organigrama público un nuevo organismo administrativo: el Gobierno Regional, persona jurídica de Derecho Público, a la cual confió "la administración superior de cada región”, precisando que a ellos correspondería en tal carácter realizar la promoción del "desarrollo social, cultural y económico de la región”, como lo dispone actualmente el inciso $2^{\circ}$ del artículo 111 del Código Político vigente.

Artículo 111, inciso $2^{\circ}$. La administración superior de cada región radicará en un gobierno regional que tendrá por objeto el desarrollo social, cultural y económico de la región.

De esta manera, la Constitución Política chilena contó por primera vez con una definición de Administración del Estado acotada desde su contenido, desde su sustantividad jurídica, como una actividad encaminada a lograr "el desarrollo social, cultural y económico", en un evidente desafío a la communis opinio imperante, puesto que tal conceptuación obligaba y obliga a replantearse desde allí el significado de esta actividad en el universo estatal, atendida la circunstancia que hasta esa fecha la precisión de su actuar y de las demás referencias e inferencias administrativas se 
hacían girar en torno a la administración como una actividad de ejecución de ley o como una actividad de servicio público, insertas dentro de la normativa del Capitulo IV relativo al Presidente de la República como autoridad nuclear llamada constitucionalmente a impartir el agua bendita y el óleo sagrado de lo administrativo en el país a los demás órganos que asumían lo administrativo en Chile, como centro irradiador que era de la virtud administrativa en la República.

El año 1991, en efecto, marcó un gran viraje constitucional en esta visión de lo administrativo en el país al consagrar ese determinado concepto de función administrativa que encierra su artículo 111 , inciso $2^{\circ}$.

Justamente, esta ley $\mathrm{n}^{\circ}$ 19.097, de 1991, que modificó el Capítulo XIII de la Constitución: "Gobierno y Administración Interior del Estado" e incorporó al ámbito administrativo a una nueva persona jurídica de base territorial, el Gobierno Regional, con la misión de ejercer "la administración superior de la región”, encargó al legislador orgánico constitucional la regulación de estas nuevas entidades, para lo cual la historia fidedigna de su establecimiento cuidó de dejar constancia qué era para el constituyente el gobierno y qué la administración.

Las Comisiones Unidas del Senado, en informe luego hecho suyo por las Comisiones Unidas de la Cámara de Diputados, precisaron estos conceptos.

"El criterio imperante para caracterizar en el texto constitucional al gobierno y a la administración, dice el informe de las Comisiones Unidas del Senado, fue-el de considerar que la función de gobierno implica la potestad de tomar decisión y es, por tanto, una facultad de imperio. Es comprensiva, también, de todo cuanto tienda a la preservación del orden público y la conservación de la seguridad interna y externa, siendo una de sus características la de poder adoptar resoluciones discrecionales."

"A su turno, la función administrativa supone un conjunto de atribuciones que se orientan más bien a la aplicación de las normas legales y decretales para la consecución de los objetivos de poder público en materia de desarrollo y funcionamiento de los servicios públicos." ${ }^{21}$

Por eso, dispuso el nuevo artículo 111 , inciso $2^{\circ}$, los Gobiernos Regionales tendrían "por objeto el desarrollo social, cultural y económico de la región”, finalidad que habrían de alcanzar fundamentalmente, por

\footnotetext{
21 Vid: Diario de sesiones del Senado, sesión 23a , celebrada en martes 6 de agosto de 1991, "Discusión particular", artículo $7^{\circ}$. Boletín de sesiones de la Cámara de Diputados, sesión 37ª, celebrada en lunes 9 de septiembre de 1991, "Discusión y votación particular del proyecto", artículo $7^{\circ}$.
} 
mandato del artículo 113, a través de "planes de desarrollo de la región", los cuales naturalmente suponen la determinación previa de políticas públicas de desarrollo regional para plasmarlas con posterioridad en lo que son planes, programas y acciones de implementación.

Artículo 111, inciso $2^{\circ}$. La administración superior de cada región radicará en un gobierno regional que tendrá por objeto el desarrollo social, cultural y económico de la región.

Artículo 113, inciso $2^{\circ}$. Corresponderá desde luego al consejo regional aprobar los planes de desarrollo de la región y el proyecto de presupuesto del gobierno regional, ajustados a la política nacional de desarrollo y al presupuesto de la Nación. Asimismo, resolverá la inversión de los recursos consultados para la región en el fondo nacional de desarrollo regional, sobre la base de la propuesta que formule el intendente.

La Ley Orgánica Constitucional de Gobierno y Administración Regional vino a viabilizar esas reglas constitucionales, desagregando en su artículo 16, letras a) e i), en lo que interesa, las facultades de implementar las respectivas políticas públicas y el deber de coordinarlas con las determinaciones superiores adoptadas en el plano nacional.

Ahora, si del plano regional se desciende al comunal, la idea rectora de lo administrativo regional es reproducida por la Constitución Política en el nivel local, como se desprende su artículo 118 , que en su inciso $4^{\circ}$ señala que la finalidad de las municipalidades como "corporaciones autónomas de derecho público", "es satisfacer las necesidades de la comunidad local y asegurar su participación en el progreso económico, social y cultural de la comuna."

Acatando las normas constitucionales, el artículo $7^{\circ}$, inciso $1^{\circ}$, de la Ley Orgánica Constitucional de Municipalidades dispone que "El plan comunal de desarrollo -es-el instrumento rector del desarrollo de la comuna”, imponiendo al alcalde la obligación de proponerlo al concejo en la primera semana del mes de octubre de cada año calendario (artículos 59 , inciso penúltimo, y 71, letra a)), y atribuyendo a este órgano colegiado la facultad de aprobar dicho plan antes del 15 de diciembre (artículo 71, letra a)). Agrega el artículo $9^{\circ}$ de la misma ley que "las municipalidades deberán actuar, en todo caso, dentro del marco de los planes nacionales y regionales que regulen la respectiva actividad".

Artículo $7^{\circ}$, inciso $1^{\circ}, 1^{\mathrm{a}}$ parte. El plan comunal de desarrollo, instrumento rector del desarrollo en la comuna, contemplará las acciones orientadas a satisfacer las necesidades de la comunidad local y a promover 
su avance social, económico y cultural.

Artículo $9^{\circ}$, inciso $1^{\circ}$. Las municipalidades deberán actuar, en todo caso, dentro del marco de los planes nacionales y regionales que regulen la respectiva actividad.

Mas: ¿qué ocurre con la aplicación de este nuevo concepto de función administrativa en el nivel nacional, dado el hecho de que las normas de 1991 alcanzaron solamente a los planos regional y local, sin alcanzar el Capítulo IV: Gobierno, que radica en el Presidente de la República las funciones de gobierno y de administración?

Ante este silencio del Código Político: ¿Debería el Presidente de la República restringir su actuación a la conservación del orden público en el interior y a la seguridad exterior del país, como lo prescribe ad pedem literae el artículo 24, inciso $2^{\circ}$, del Código Político, o adaptarse a la nueva concepción constitucional?

Al margen de que en el campo del Derecho Público no es admisible aplicar interpretaciones analógicas, lo que veda por consiguiente cualquier alcance extensivo que quiera atribuirse a los preceptos ya vistos en el orden regional y local para aplicarlos per se al nivel nacional, desde el punto de vista de la razonabilidad jurídica parece contraproducente sostener en principio que lo que es función administrativa en los planos regional y local no lo sea en el nivel nacional, más aún teniendo presente la jurisprudencia del Tribunal Constitucional, que ha concluido, v. gr., en su fallo Rol no 46, de 1987, que "La constitución es un todo orgánico y el sentido de sus normas debe ser determinado de manera tal, que exista entre ellas la debida correspondencia y armonía, excluyéndose cualquiera interpretación que conduzca a anular o privar de eficacia algún precepto de ella.”

Con todo, es efectivo que la Carta Política no consulta disposición constitucional alguna que radique explícitamente en el Presidente de la República la facultad de fijar la política nacional de desarrollo y consiguientemente la de elaborar los planes, programas y acciones necesarios para viabilizarla, ya que como se anticipara, el legislador de la ley $\mathrm{n}^{\circ} 19.097$ omitió modificar el Capítulo IV de la Carta Política sobre las atribuciones del Jefe de Estado.

Cabe preguntarse, pues: ¿Existe, en esta materia, una "correspondencia y armonía”, esa conectividad interna que permita conceptuar a la función administrativa del Estado dentro de "un todo orgánico" constitucional?

Todo indica que sí. 
Desde luego, ha de recordarse que en la práctica, nunca se ha puesto en duda en el país la facultad implícita que de todas maneras asiste al Presidente de la República para elaborar, aprobar y ejecutar la política de desarrollo del país. Así lo reconoció el Tribunal Constitucional antes de la reforma de 1991, en su sentencia de 10 de octubre de 1989, Rol n ${ }^{\circ} 78$, al decir "que de acuerdo con el artículo 24 de la Constitución Política, el Presidente de la República es el encargado del gobierno de la Nación, y, en tal consecuencia, le compete la dirección superior de los intereses generales de ésta", facultad que le habilita para "fijar la política tributaria, arancelaria, presupuestaria, de fijación de precios, de remuneraciones, de creación de servicios públicos, de recaudación de las rentas públicas y de su inversión con arreglo a la ley, de seguridad social y negociación colectiva; la política minera, agropecuaria, forestal, pesquera, etc.”.

Desde otra perspectiva, no es difícil comprobar que en la reforma del año 1991, cuyos términos políticamente consensuados incluso se documentaron, el constituyente pecó de un exceso de confianza y en una inadecuada técnica legislativa.

Exceso de confianza, pues dio por subentendido que la aprobación de los planes de desarrollo era una materia propia de la competencia presidencial, como que desde hace años los ministerios habían estado aprobando directrices de corto y mediano plazo para programar sus actividades, a tal punto que la LOCBGAE, que es del año 1986, desde su dictación previno en su artículo 19 (actual 22), inciso $2^{\circ}$, que los Ministros, en su calidad de colaboradores del Presidente de la República, "deberán proponer y evaluar las políticas y planes correspondientes" a su sector, debiendo entenderse, como es natural, que esa proposición habría de ser elevada al Primer Mandatario, para que una vez aprobada por él se procediera a su evaluación posterior por el Ministro, es decir, a la medición de sus condiciones de implementación y cumplimiento de las directrices en ella contenidas.

Asimismo, desde 1986, la LOCBGAE impuso a las autoridades administrativas en su artículo 11, actual 12, la obligación "de velar permanentemente por el cumplimiento de aquellos - de los planes - y la aplicación de éstas - de las normas - dentro del ámbito de sus atribuciones, sin perjuicio de las obligaciones propias del personal de su dependencia", definiendo a los servicios públicos como "órganos administrativos encargados de satisfacer necesidades colectivas, de manera regular y 
continua", que se entenderían con el Presidente de la República "a través de los respectivos Ministerios, cuyas políticas, planes y programas les corresponderá aplicar”, como lo preceptuó el artículo 25 (actual 28) de esa LOCBGAE, reiterando de esta manera la evidente existencia de políticas y planes de desarrollo, la titularidad presidencial de su aprobación, el deber ministerial de su proposición y evaluación y la obligación funcionaria, en todos los planos de la jerarquía interna de los servicios, de darles íntegro y cabal cumplimiento.

Inadecuada técnica jurídica acusa también el constituyente en su formulación de 1991, porque el reconocimiento de una política nacional de desarrollo que insertó en el texto político, lo hizo en una forma referencial, no atributiva, en esa frase intercalada que se aprecia en el inciso $2^{\circ}$ del actual artículo 113, sin darle respaldo alguno en el Capítulo IV, que es el módulo constitucional que contiene la regulación presidencial del "gobierno y la administración" del Estado, y donde nada se decía ni se dice al respecto.

No puede celebrarse, en verdad, que una modificación tan importante como la redefinición de la función administrativa dispuesta por el legislador de la ley $\mathrm{n}^{\circ} 19.097$ se haya insertado en el Texto Fundamental a través de esa frase contenida por lo demás en un artículo ubicado al final de la Constitución Política, a propósito de la facultad otorgada a los consejos regionales de aprobar los planes de desarrollo regional, sin cuidar de enlazar este nuevo concepto de lo administrativo con las normas de ese Capítulo IV, "Gobierno", en que se detallan las atribuciones del Presidente de la República, hasta ese momento la única figura representativa de lo administrativo en el país.

Haciendo una interpretación que supla la imposibilidad de aplicación del texto fundamental y siguiendo la simetría que demanda el Tribunal Constitucional para la hermenéutica de la Carta Política, ha de destacarse, ante todo, como primer gran criterio de aproximación a una solución objetiva del tema planteado por el Código Político, la dinámica de determinación de competencias públicas que contiene la Constitución: en una de las innovaciones que la Carta Fundamental de 1980 incorporó a la constitución chilena tradicional, y que hizo suya la de 2005, las materias legislativas están estrictamente señaladas en el texto del artículo 63, de manera que sólo son legislables las materias allí mencionadas en lista cerrada por el constituyente.

Dispuso, a su vez, la Constitución, que las materias no contempladas 
en ese carácter por el artículo 63, serían de la competencia del administrador, del Presidente de la República, prescribiéndolo así en su artículo 32 , numeral $6^{\circ}$, que complementa aquella disposición.

Artículo 63. Sólo son materias de ley:

Artículo 32. Son atribuciones especiales del Presidente de la República:

$6^{\circ}$. Ejercer la potestad reglamentaria en todas aquellas materias que no sean propias del dominio legal, sin perjuicio de la facultad de dictar los demás reglamentos, decretos e instrucciones que crea convenientes para la ejecución de las leyes.

Estando precisamente acotado el campo de la competencia legislativa en el artículo 63 del Código Político, y correspondiendo al administrador regular "todas aquellas materias que no sean propias del dominio legal”, en los términos del artículo 32 numeral $6^{\circ}$ de la misma Carta, se clarifica entonces el iter fijado por el constituyente para establecer la competencia de las autoridades legislativa y administrativa, pues si la materia de que se trata se encuentra enumerada en el artículo 63 es un asunto de competencia legislativa, y de no ser así, lo será de competencia administrativa presidencial.

Como la aprobación de la política nacional de desarrollo no se encuentra consultada en ese artículo 63, es lícito concluir, entonces, que la elaboración, aprobación, ejecución y control de las políticas públicas de desarrollo y de los consiguientes planes, programas y acciones que se aprueben y realicen para ejecutarlas, corresponde decidirlos al Presidente de la República en el plano nacional, sin perjuicio de que por mandato de que la Constitución Política corresponda ejercer esas potestades públicas a los Gobiernos Regionales y a las Municipalidades en los niveles regional y comunal o local, en tanto y en cuanto confía precisamente a ellos en esas circunscripciones territoriales, las facultades de elaborar, aprobar, ejecutar y controlar los respectivos planes, programas y acciones que implementen las correspondientes políticas públicas en esos niveles.

V La Sustancialidad de los Derechos en su Proyección Funcional Administrativa: El desarrollo personal de todos los miembros de la comunidad nacional

7 La modificación constitucional del año 1991 permite descartar como clave de bóveda en la definición de la función administrativa a nivel constitucional, a las solas ideas de servicio público y de garantía de los

A \& C R. de Dir. Administrativo \& Constitucional, Belo Horizonte, ano 8, n. 31, p. 180-198, jan./mar. 2008 
derechos de los particulares ante la autoridad administrativa, para presentarla como una actividad de servicio público y de desarrollo nacional, regional y comunal, en los términos del informe de las Comisiones Unidas del Senado a propósito de la ley no 19.097.

Sin embargo, no es ésta la única perspectiva que orienta a la Constitución Política, ya que con base en los artículos $1^{\circ}, 5^{\circ}$ y 113 , se advierte en ella, al año 2005, la imposición al Estado de un deber de estar "al servicio de la persona humana", y la asignación a él, como finalidad propia, la de "contribuir a crear las condiciones sociales que permitan a todos y a cada uno de los integrantes de la comunidad nacional su mayor realización espiritual y material posible, con pleno respeto a los derechos y garantías que esta Constitución establece" (artículo $1^{\circ}$, inciso $4^{\circ}$ ); una categórica afirmación de los derechos de las personas aún por sobre el ejercicio de la soberanía reservado a los órganos del Estado (artículo $5^{\circ}$, inciso $2^{\circ}$ ); y una nítida redefinición de la función administrativa tradicional, para orientarla ahora a la prestación de servicios públicos y al desarrollo social, cultural y económico de la nación, de las regiones y de las comunas, y, como consecuencia de lo expresado, al incorporar el humanismo y la solidaridad como elementos valóricos componentes del orden jurídico chileno (artículo $1^{\circ}$, incisos $4^{\circ}$ y $5^{\circ}$ ), ideas fuerza que impactan decisivamente el concepto que la doctrina y la jurisprudencia nacionales habían estructurado como administrativo con anterioridad a estas profundas vivencias transformadoras del ser jurídico chileno.

Artículo $1^{\circ}$, incisos $4^{\circ}$ y $5^{\circ}$. El Estado está al servicio de la persona humana y su finalidad es promover el bien común, para lo cual debe contribuir a crear las condiciones sociales que permitan a todos y a cada uno de los integrantes de la comunidad nacional su mayor realización espiritual y material posible, con pleno respeto a los derechos y garantías que esta Constitución establece.

Es deber del Estado resguardar la seguridad nacional, dar protección a la población y a la familia, propender al fortalecimiento de ésta, promover la integración armónica de todos los sectores de la Nación y asegurar el derecho de las personas a participar con igualdad de oportunidades en la vida nacional.

Artículo $5^{\circ}$, inciso $2^{\circ}$. El ejercicio de la soberanía reconoce como limitación el respeto a los derechos esenciales que emanan de la persona humana. Es deber de los órganos del Estado respetar y promover tales 
derechos, garantizados por esta Constitución, así como por los tratados internacionales ratificados por Chile y que se encuentren vigentes.

En estas circunstancias, reconociendo las insuficiencias antes anotadas de la regulación constitucional de la función administrativa en el Chile actual, bien puede asegurarse que su concepto no puede ser acotado como lo hace la doctrina, ajustándolo a la idea de servicio público o a la de ejecución de la ley, ya que al construirla con las piezas positivas, sustanciales y teleológicas que contiene el Código Político de 2005, ella se yergue en la institucionalidad contemporánea como una actividad del Estado orientada a la prestación de servicios públicos y a la promoción, tanto del desarrollo general -social, cultural y económico-del país, de las regiones y de las comunas, cuando al desarrollo personal de todos los miembros que integran la sociedad, contribuyendo a que alcancen "su mayor realización espiritual y material posible".

Informação bibliográfica deste texto, conforme a NBR 6023:2002 da Associação Brasileira de Normas Técnicas (ABNT):

PANTOJA BAUZÁ, Rolando. La Función Administrativa en la Constitución Chilena. A\&C Revista de Direito Administrativo e Constitucional, Belo Horizonte, ano 8, n. 31, p. 180-198, jan./mar. 2008. 